\title{
Correction to: Role split phenomenon of academic staff in Chinese higher education: a case study of Fudan University
}

\section{Du Xiaoxin ${ }^{1}$}

Published online: 13 September 2018

(C) Springer Nature B.V. 2018

\section{Correction to: Higher Education \\ https://doi.org/10.1007/s10734-017-0180-7}

The original version of this article unfortunately contained a mistake. The corrections are as follows:

1) In the Abstract section, "Hong Kong SAR, People's Republic of China (PRC)" should instead be "Shanghai, People's Republic of China (PRC)".

2) In page 10, 3rd paragraph, 4th line, the "FUD" in "...Year 2 students (Interview/FDU08) reported that he was initially surprised that FUD's classes..." should be changed to "FDU" so the sentence should now read: "Year 2 students (Interview/FDU08) reported that he was initially surprised that FDU's classes".

The online version of the original article can be found at https://oi.org/10.1007/s10734-017-0180-7

Du Xiaoxin

xxdu@ connect.hku.hk

1 Faculty of Education, The University of Hong Kong, Room 401, Runme Shaw Building, Hong Kong SAR, China 